\title{
Xantogranuloma sintomático del ventrículo lateral. A propósito de un caso
}

\author{
I. Insausti; T. Cabada; C. Caballero*; I. Zazpe**; M.C. Bacaicoa y J. Olier
}

Servicios de Radiodiagnóstico, Anatomía Patológica* y Neurocirugía**. Hospital de Navarra. Pamplona.

\section{Resumen}

El xantogranuloma del plexo coroideo es un tumor benigno de etiología incierta, que generalmente es asintomático. Presentamos un caso de xantogranuloma del atrio ventricular izquierdo sintomático con edema de la sustancia blanca adyacente, en un paciente varón de 62 años con crisis comiciales de inicio reciente.

PALABRAS CLAVE: Xantogranuloma. Tumor de los ventrículos laterales. RM.

Symptomatic xanthogranuloma of the lateral ventricle

\section{Summary}

Xanthogranulomas of the choroid plexus is a benign tumour of uncertain etiology, usually asymptomatic. We report a case of symptomatic xanthogranuloma of the left lateral ventricle with edema in adyacent white matter, in a 62-year-old man with seizures.

KEY WORDS: Xanthogranuloma. Lateral ventricle tumours. MRI.

\section{Introducción}

Los xantogranulomas son tumoraciones compuestas por células con alto contenido lipídico, generalmente histiocitos, asociados a una población mixta de células gigantes, fibroblastos, células inflamatorias crónicas, y hemosiderina.

Generalmente son hallazgos incidentales de autopsia (1,6 $-7 \%$ de las autopsias $)^{5}$, ya que la mayoría son asintomáticos ${ }^{1}$. Presentamos un caso de xantogranuloma de ventrículo lateral sintomático con hallazgos particulares en TC y RM.

\section{Caso}

Paciente de 62 años, sin antecedentes de interés, que

Recibido: 26-06-07. Aceptado: 4-05-08 presenta de forma súbita dos episodios comiciales tardíos, con fractura de hombro derecho en una de ellas.

Tanto los datos de laboratorio como las exploraciones físicas y neurológicas fueron normales.

La TC craneal mostró una lesión ovalada de 1,5 x 1,5 x $2 \mathrm{~cm}$. de diámetro, localizada en atrio ventricular izquierdo (figura 1). Dicha lesión estaba calcificada prácticamente
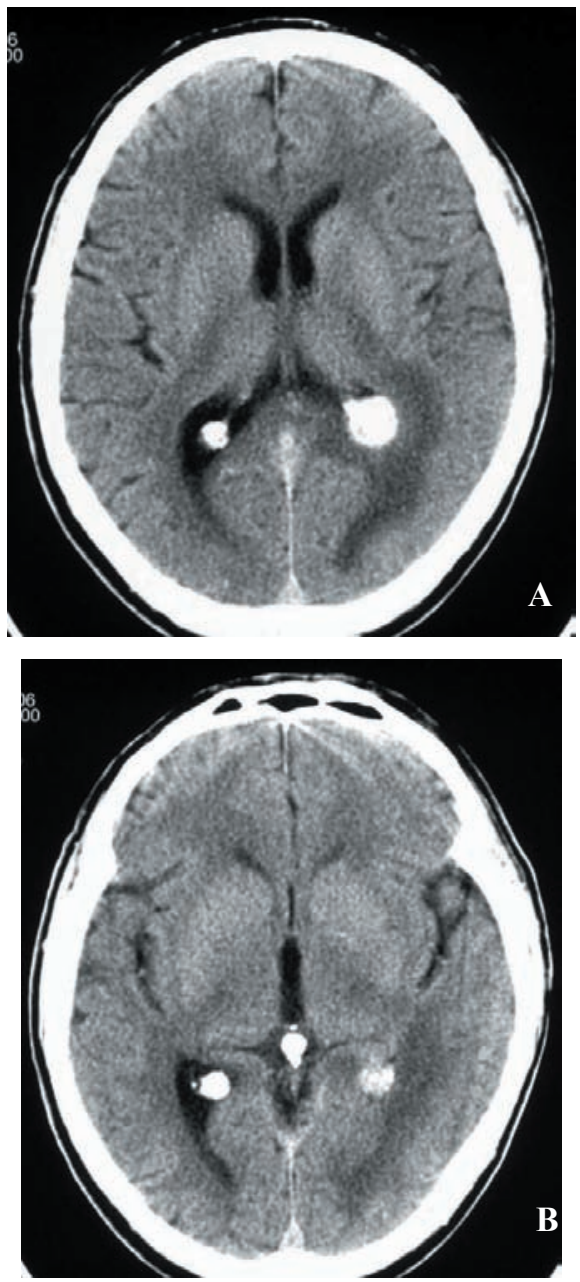

Figura 1 (a, b). TC craneal sin contraste i.v. Se observa una lesión ovalada calcificada localizada en atrio ventricular izquierdo, con hipodensidad de la sustancia blanca adyacente. 


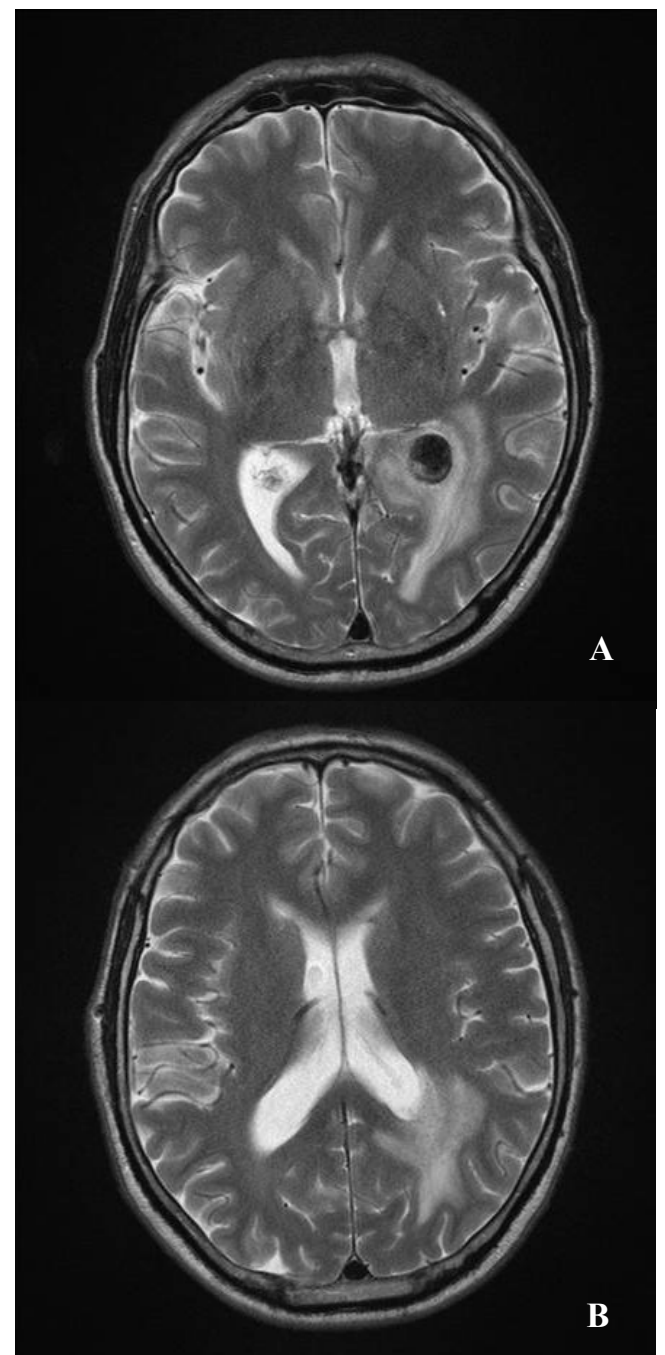

Figura 2 (a,b). Imágenes axiales en secuencias TSE potenciadas en $T 2$ (TR=4000 TE=98). A) lesión nodular localizada en plexo coroideo del atrio ventricular izquierdo, bien definida, que presenta una marcada hiposeñal. B) alteración de la señal de la sustencia blanca parietooccipital izquierda.

en su totalidad. Se observaba asimismo una hipodensidad en la sustancia blanca adyacente. No existía dilatación ventricular.

La RM craneal reveló una lesión nodular localizada en el atrio ventricular izquierdodo, en relación con el plexo coroideo. La lesión se encontraba bien definida y presentaba una marcada hiposeñal en las secuencias T2 (figura 2) y una señal intermedia en $T 1$, apreciándose un realce intenso y heterogéneo tras la administración de gadolinio (figura 3). La hipointensidad referida en T2 se interpretó como secundaria a la densa calcificación descrita en la TC. Así mismo se observó una alteración de señal importante en el parénquima adyacente al atrio ventricular y al asta
2009; 20:278-281

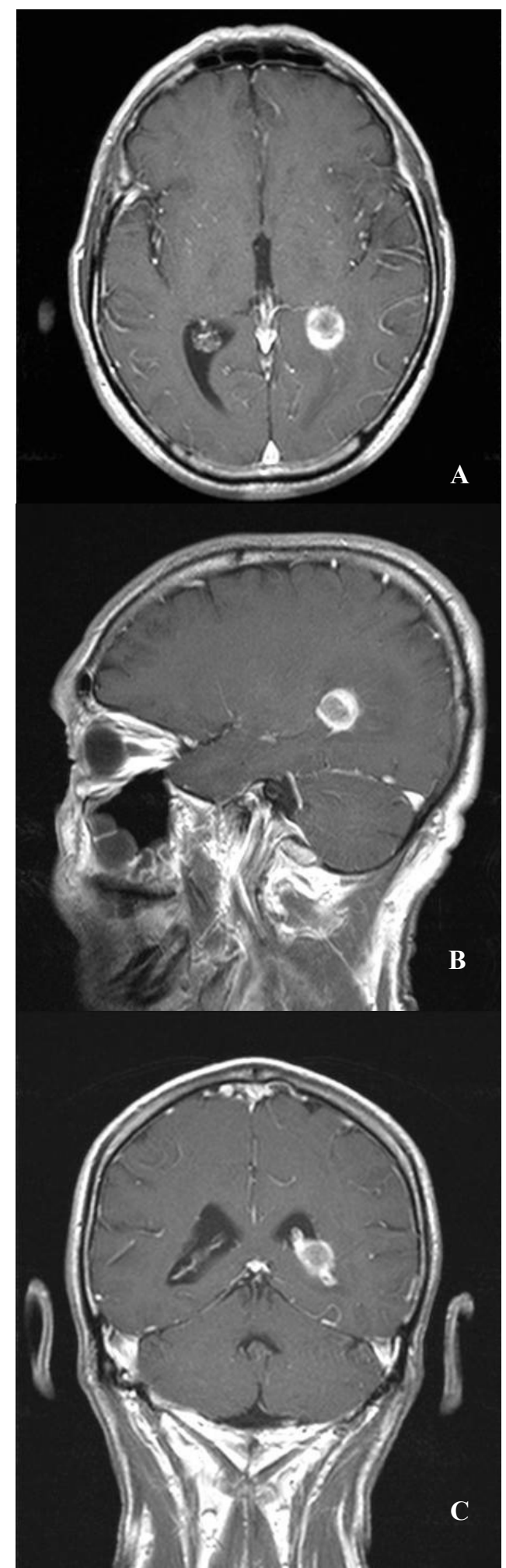

Figura $3(\mathrm{a}, \mathrm{b}, \mathrm{c})$. Imágenes en secuencias SE potenciadas en $T 1$ (TR=525, TE=17) tras la administración de gadolinio. Los cortes axial (a), sagital (b), y coronal (c), muestran un realce intenso y hetereogéneo de la lesión. 


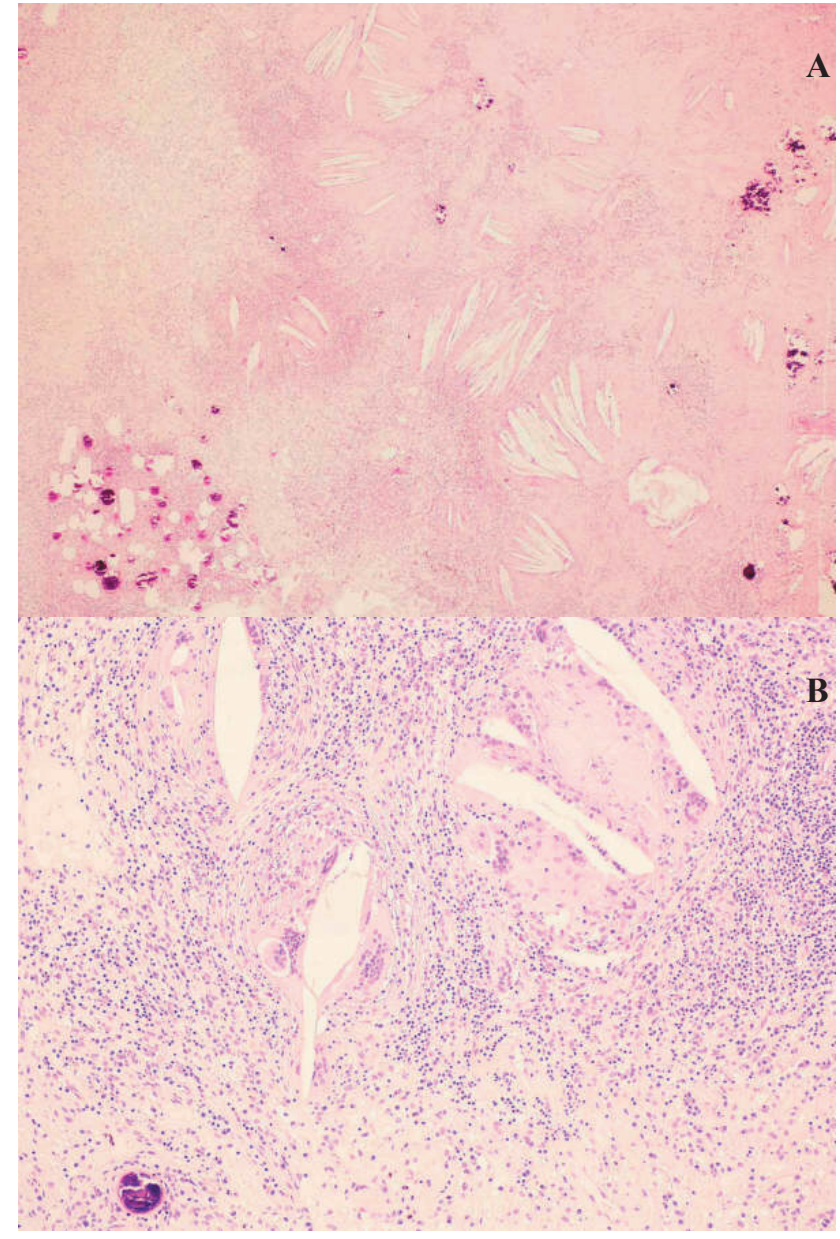

Figura 4 (a, b. A) microfotografía panorámica en la que se observa fibrosis, focos de inflamación, reacción gigantocelular frente a cristales de colesterol y calcosferitas ( $H \& E$, $x$ 4). B) detalle en la que se observa en la periferia del nódulo con fribosis e inflamación y restos de parénquima cerebral (H\&E, x 20).

occipital, con prolongación de señal en T1 y T2, sin realce con gadolinio, lo que confirmó un edema vasogénico secundario.

Se realizó una panangiografía cerebral que fue normal.

El paciente fue intervenido mediante craniectomía temporo-occipital izquierda guiada por neuronavegador, llegando hasta el atrio de ventrículo lateral izquierdo, con extirpación total de una tumoración dependiente del plexocoroideo de dicho ventrículo.

El examen histológico de la pieza quirúrgica reveló un nódulo de tejido fibroso denso en la zona periférica, con áreas colagenizadas en la zona central en la que se observaban células espumosas y reacción gigantocelular de tipo cuerpo extraño frente a cristales de colesterol. Se observó intenso infiltrado inflamatorio crónico constituido por linfocitos y células plasmáticas con ocasionales acúmulos linfoides. Se visualizaron calcosferitas. Asimismo en la periferia de la lesión existían restos del epitelio de plexo coroideo, y se reconoció una pequeña área de sustancia blanca con cuerpos amiláceos. No se observaron signos de malignidad (figura 4).

La TC de control mostró desaparición de la lesión del atrio ventricular izquierdo con persistencia del edema vasogénico en el parénquima adyacente. El paciente presentó un postoperatorio favorable, presentando una disfasia nominal transitoria y una cuadrantanopsia homónima derecha, que persistía a los 2 meses de seguimiento.

\section{Discusión}

El xantogranuloma es un tumor benigno, hallazgo frecuente en los estudios postmorten. La localización más habitual es en los ventrículos laterales, y suelen ser asintomáticos ${ }^{1}$. Sin embargo, los xantogranulomas localizados en el III ventrículo pueden ser más frecuentemente sintomáticos por su capacidad para obstruir los agujeros de Monroe y producir hidrocefalia.

La patogénesis del xantogranuloma es controvertida. Ciertos autores (Bruck et $\mathrm{al}^{2}$ y Miranda et $\mathrm{al}^{5}$ ) sostienen como mecanismo patogénico los cambios inflamatorios debido a la invaginación y proliferación del plexo coroideo o la presencia de hemorragias intralesionales. El plexo coroideo está formado por ejes fibrovasculares revestidos por una capa de células epiteliales cúbicas, que con el envejecimiento tienden a la estratificación y a presentar metaplasia escamosa. Las células espumosas del xantogranuloma pueden derivar de las células escamosas del epitelio coroideo que penetran el estroma en las zonas de interrupción de la membrana basal o de los histiocitos locales. En cualquier caso, se produce la liberación de lípidos, y se forman cristales de colesterol, lo que a su vez desencadena una mayor respuesta granulomatosa. Los xantogranulomas del III ventrículo son más frecuentemente quísticos y rodeados de epitelio, y se asocian con los quistes coloides, por lo que algunos autores los consideran relacionados con los quistes neuroepiteliales ${ }^{1}$.

Radiológicamente, los xantogranulomas se han descrito como lesiones localizadas en los ventrículos laterales, hipodensas en los estudios de TC basal (por el contenido graso), con calcificaciones estromales, similares a las calcificaciones fisiológicas del plexo coroideo, y sin realce tras la administración de contraste ${ }^{5}$. Sin embargo, en la literatura se han comunicado apariencias diversas con lesiones iso o hiperdensas ${ }^{1}$ respecto al parénquima y presencia de realce parcial o intenso ${ }^{1,4}$. Respecto a la RM, existen menos datos publicados, aunque se ha descrito la presencia de un patrón de señal iso o hiperintenso en T1 e hiperintenso en T2 (por las áreas de grasa y hemorragia) con realce variable tras la administración de gadolinio ${ }^{1}$. 
La presencia de edema parenquimatoso secundario a estas lesiones se ha descrito en muy pocos casos y algunos con afectación parenquimatosa directa por el tumor. En la literatura se han recogido, al menos 3 localizados en el ventrículo lateral y uno en el III ventrículo ${ }^{1,3,6}$. Otros autores han sugerido la desmielinización de la sustancia blanca para justificar la hiperintensidad en las secuencias potenciadas en $\mathrm{T}^{3}$.

En el caso presentado, es reseñable la presencia de signos de edema en el parénquima circundante, en ausencia de hidrocefalia, lo que se interpretó como un signo de agresividad biológica, y relacionado con la clínica del paciente. La ausencia de hipodensidad en la TC, se podría explicar por la presencia de una calcificación densa. Este hallazgo justificaría asimismo la hipointensidad marcada en las secuencias potenciadas en T2 de la RM, no descrita en otros casos publicados. También cabe destacar el grado de realce observado que fue intenso y relativamente homogéneo. La ausencia de vascularización patológica en la angiografía apoyaría el carácter benigno de la lesión.

En el diagnóstico diferencial de las masas del plexo coroideo se incluyen el papiloma y carcinoma del plexo, meningioma, lesiones vasculares, metástasis y el xantogranuloma ${ }^{5}$. Los papilomas de plexo coroideo son raros y más frecuentes en niños, observándose en adultos especialmente en el IV ventrículo. Los meningiomas son lesiones densamente calcificadas que pueden localizarse en el plexo y presentan realce intenso, pudiendo afectar al parénquima adyacente. Dentro de las malformaciones vasculares se incluyen hemangiomas y malformaciones arteriovenosas y su diagnóstico se confirma mediante angiografía. Las lesiones metastásicas no son excepcionales, por lo que se debe valorar la presencia de una neoplasia primaria extracraneal.

En resumen el xantogranuloma de plexo coroideo es un tumor benigno, habitualmente asintomático, que presenta una apariencia característica en los estudios radiológicos. No obstante no se puede olvidar que puede ser sintomático y presentarse con signos de afectación del parénquima, por lo que estos datos no deben excluirlos del diagnóstico diferencial de las tumoraciones del plexo coroideo.

\section{Bibliografía}

1. Bert Lincoln Pear: Xanthogranuloma of the Choroid Plexus. AJR 1984; 143: 401-402.

2. Bruck, W., Sander, U., Blanckenberg, P., Friede, R.L.: Symptomatic xanthogranuloma of choroids plexus with unilateral hydrocephalus. Case report. J. Neurosurg.1991; 75: 324-327.

3. Hicks, M.J., Albrecht, S., Trask, T., Byrne, M.E., Narayan, R.K., Goodman, J.C.: Symptomatic choroids plexus xanthogranuloma of the lateral ventricle. Case report and brief critical review of xanthogranulomatous lesions of the brain. Clinical Neuropathology. 1993; 12: 92-96.

4. Handagoon, P., Pitakdamrongwong, N., Shuangshoti, S.: Xanthogranulomas of choroid plexus. Neuroradiology. 1987; 29: 172-173.

5. Miranda, P., Lobato, R.D., Ricoy, J.R., Lagares, A., Ramos, A.: Xanthogranuloma of the choroid plexos of the third ventricle: case report and literatura review. Neurocirugía 2005; 16: 517-522.

6. Tsuyoshi Kadota, Naoki Mihara, Naoko Tsuji, Shingo Ishiguro, Hidemitsu Nakagawa, Chikazumi Kuroda. AJNR 17: 1595-1597.

Insausti, I.; Cabada, T.; Caballero, C.; Zazpe, I.; Bacaicoa, M.C.; Olier, J.: Xantogranuloma sintomático del ventrículo lateral. A propósito de un caso. Neurocirugía 2009; 20: 278-281.

Corrrespondencia postal: Iñigo Insausti Gorbea. Servicio de Radiodiagnóstico. Hospital de Navarra. Irunlarrea 3. 31008 Pamplona-Iruña. 